\title{
DOES PRACTICE MAKE PERFECT: AN EMPIRICAL ANALYSIS OF LEARNING-BY-DOING IN CARDIAC SURGERY
}

\author{
Subramaniam Ramanarayanan ${ }^{1,2}$ \\ UCLA Anderson School of Management
}

\begin{abstract}
This paper examines a mechanism through which workers acquire and maintain competence: task experience. I analyze whether cardiac surgeons who have performed more procedures in the recent past experience an improvement in performance. I use an instrumental variables method that considers exogenous shocks to the procedure volume of CABG surgeons in Florida caused by the exit of other surgeons from the same hospital. I find evidence indicating a strong learning-by-doing effect: performing an additional procedure reduces the probability of patient mortality by $0.14 \%$. This benefit is lower for high volume surgeons, and is partly specific to firm and task settings.
\end{abstract}

\footnotetext{
${ }^{1}$ This paper is based on Chapter 1 of my dissertation submitted to Northwestern University. I am grateful to David Dranove and Leemore Dafny for their advice and invaluable support and encouragement. I would also like to thank David Besanko, Shane Greenstein, Vivian Ho, Tom Hubbard, Mike Mazzeo, Sanjog Misra, Hayagreeva Rao, Joel Shalowitz, Scott Stern, seminar participants at the Kellogg School of Management, MIT Sloan School of Management, Yale School of Management, Wharton, London Business School, Cornell University, Rochester University, UCLA, Rice University, University of Houston and conference participants at the 2006 meeting of the American Society of Health Economists for helpful comments and suggestions.

${ }^{2}$ Email: subbu@anderson.ucla.edu
} 


\section{Introduction}

The effects of organizational experience on quality and costs have been studied in multiple settings. The realization of productivity gains with increased experience is termed learningby-doing and the presence of a learning curve has been well documented in manufacturing and service firms. However, the extent of our knowledge about why learning occurs is still limited. For example, learning could result from the acquisition of human capital by individual employees or from increased organizational experience that helps standardize production processes. In this paper, I analyze one of the determinants of worker competence in an organizational setting: task experience. I use the term experience here to connote frequency of performing a certain task, as opposed to number of years spent on the job.

In industries employing skilled labor, learning is thought to result mainly from workers becoming more efficient at the tasks they perform through multiple repetitions. I study learning-by-doing at the level of the individual worker in one such setting, specifically that of cardiac surgeons performing Coronary Artery Bypass Graft (CABG) surgeries in hospitals. In particular, I estimate the extent to which a surgeon's recent procedure volume (measured as the number of $\mathrm{CABG}$ surgeries performed the previous year) affects performance (measured by patient outcomes). In addition, the setting of this study enables me to test for the degree of specificity (to a firm and to a task) of human capital that is acquired by individuals through learning-by-doing.

Focusing on individual experience provides interesting insights into the learning process of firms. Recent research in the field of organizational learning has focused on the differences in learning rates across organizations (e.g. Pisano et al (2001); Reagans et al (2005)), and proficiency of individual workers has been identified as one of the factors driving this variation. The results from this study can also help shape a firm's strategy on hiring and retention of skilled workers and on allocation of workload across workers. In addition, the study addresses an issue that is extremely relevant to the health care sector where provider experience has long been used as a proxy for quality by patients, health care providers, surgical accreditation boards and insurers. Procedure volume also plays a prominent role in 
hospital marketing brochures and websites, suggesting that it is a metric widely used within the industry to signal quality.

Given the significance attached to provider experience in health care, there is surprisingly little convincing empirical evidence that establishes the presence of learning-by-doing in this setting. Estimates from prior studies are confounded by a fundamental problem of identification: Does experience result in learning or does quality reflect unobserved skills resulting in greater demand, and thus greater experience? In other words, do surgeons improve with experience or are high quality surgeons more experienced because they attract more patients? Existing studies in the healthcare literature assume the presence of a correlation between surgeon experience and quality as being indicative of a learning effect. Failure to account for reverse causality in these papers leads to biased estimates of learningby-doing.

I use an instrumental variables approach in this study to establish a causal relationship between surgeon procedure volume and patient outcomes. I propose the use of surgeon exit as an exogenous identifier, where the term "exit" connotes an instance where a surgeon stops performing cardiac surgeries. ${ }^{3}$ The rationale behind the instrument is as follows: once exit occurs, patients who would have been treated by the exiting surgeon are now allocated among the remaining (non-exiting) surgeons at the hospital, thereby providing a positive shock to their procedure volumes. By looking at the change in surgeon quality resulting from this shock, I am able to disentangle the learning-by-doing effect from other potential explanations underlying the volume-outcome relationship.

I make use of a patient-level dataset from the Agency of Health Care Administration (AHCA) in Florida that identifies the unique license number of the operating surgeon. By using the volume of exiting surgeons as an instrument for surgeon procedure volume, I find evidence in support of a strong learning-by-doing effect for CABG surgeons: performing a single additional procedure in the prior year yields a reduction in the probability of an adverse patient outcome of .0051 percentage points, which translates to a $0.14 \%$ drop (relative to the average mortality rate for CABG of $3.72 \%$ ). This result is fairly robust to

\footnotetext{
${ }^{3}$ I observe surgeons performing cardiac procedures in the state of Florida. I restrict the set of exiting surgeons to those who are aged at least 55 in order to decrease the likelihood that a surgeon exited a hospital for reasons relating to poor quality. Section 4 presents a more detailed discussion.
} 
alternate definitions of exit, alternate empirical specifications and to different methods of allocating the procedure volume of exitors among non-exiting surgeons. Also, surgeons performing a large volume of procedures seem to benefit less from additional experience when compared to surgeons with low procedure volume.

I extend this methodology to examine the degree of specificity (to a firm and to a task) of human capital acquired by surgeons as a result of learning-by-doing. In order to test for firm-specificity, I exploit the fact that cardiac surgeons are affiliated with (and perform procedures at) multiple hospitals at the same point in time. This allows me to use hospitalspecific measures of surgeon experience and enables me to test whether surgeon performance is affected more by experience at the current hospital than by experience at other hospitals. In order to resolve problems of endogeneity, I instrument for hospitalspecific experience using a simple modification of the instrument described above. The estimates from this specification indicate that the improvement in surgeon performance is only partly transferable across different hospital settings. Since cardiac surgeons perform procedures other than CABG surgeries, I am also able to test whether experience with nonCABG procedures benefits surgeon performance in CABG by using an estimation strategy similar to the one used to test for firm-specificity. The results indicate that greater experience performing non-CABG procedures does benefit outcomes of CABG patients, but this effect is smaller than the effect of experience performing CABG procedures, i.e. there is some degree of task-specificity to the human capital of surgeons gained from procedure experience.

Taken together, these findings have important implications for managers within the hospital industry. While allocating procedure volume within a team, it is important for managers to bear in mind that the marginal benefit of additional experience is greater for low volume surgeons when compared to high volume surgeons. Hospitals should ensure that lowvolume surgeons get to develop mentoring relationships with more experienced surgeons. The findings on firm- and task-specificity have implications for hiring and retention policies and optimal job design, respectively.

The rest of this paper is organized as follows. The next section provides a review of the streams of literature related to this study, while Section 3 describes the data and provides 
some institutional background. Section 4 outlines the empirical approach followed and describes the instrument in detail. Section 5 presents the main empirical specifications. The final two sections contain a discussion of results and some concluding remarks.

\section{Background and Related Research}

The present study draws from two streams of related research - studies of learning-by-doing in the industrial organization literature, and volume-outcome studies in the fields of medicine and health economics.

\subsection{The Benefits of Experience}

Starting with Wright's (1936) seminal analysis of airframe production, there has been a significant body of empirical and theoretical research aimed at documenting the association between cumulative experience (typically measured by cumulative production volume) and performance improvement across different industries. Some recent settings in which learning curves have been studied include aircraft production (Benkard (2000)), shipbuilding (Argote, Beckman and Epple (1990), Thompson (2001, 2006)), semiconductors (Hatch and Mowery (1998)) and pizza franchises (Darr, Argote and Epple (1995)). ${ }^{4}$ These firm-level studies examine the impact of learning-by-doing using unit costs as a measure of performance. I exploit the availability of detailed micro-level data on patients undergoing CABG surgery to study the process of learning at the level of the individual worker. Also, unlike the studies mentioned above, I characterize performance in terms of patient outcomes (or surgeon quality), which, compared to costs, are measured with greater precision in this setting.

The effect of experience on individual productivity has been investigated to a lesser extent in these literatures. ${ }^{5}$ In the setting I examine, there are a number of ways in which individual experience could matter in determining performance. The skill of the operating CABG surgeon is critical in ensuring a successful procedure. According to the American College of

\footnotetext{
${ }^{4}$ Some of these studies (e.g. Benkard (2000)) also explicitly model the effects of organizational "forgetting". ${ }^{5}$ The literature in psychology has numerous studies on this effect. These studies typically find that individuals complete a task in lesser time and with greater accuracy, the more experience they have with the task. They also find support for diminishing returns of experience. Examples include Newell and Rosenbloom (1981), Delaney, Reder, Staszewski and Ritter (1998).
} 
Cardiology ${ }^{6}$, experience has a strong influence on a surgeon's cognitive knowledge base and technical skills, both of which determine competence. Experience helps surgeons in selecting the appropriate treatment strategy for patients, and helps them identify and treat complications at an early stage. Experience also has a positive impact on manual dexterity and helps surgeons maintain proper surgical technique. Finally, because of the rare occurrence of adverse outcomes, surgeon competence requires specific training and ongoing experience in managing them so as to be prepared to react optimally when they occur.

The data in this study also allow me to estimate whether human capital acquired by individuals through learning-by-doing is specific to (a) the firms they work in and (b) the tasks they perform. In doing so, this study adds to the empirical evidence establishing learning-by-doing as a source of general or specific human capital.

For a cardiac surgeon, general human capital would result from investment in medical school, residency and post-residency training. Another determinant of the level of human capital could be procedure experience, which may help the surgeon develop new skills or maintain old ones. Studies in the human capital literature typically use earnings or wages as their measure of productivity. Since I do not have access to earnings data for surgeons, I use surgeon performance to test for specificity of human capital.

Why may one expect accumulated human capital to be (completely or partially) specific to a firm (hospital) in this setting? Huckman and Pisano (2006) offer some potential explanations, the primary one being that a surgeon tends to develop a degree of familiarity with the rest of the surgical team and other assets at a hospital and this aspect prevents the benefits of experience from being portable across hospitals. On the other hand, if familiarity were not as important as, say, learning how to treat complications, one can imagine a situation where experience adds to both general and firm-specific aspects of human capital, but the general component is much larger.

Part of the human capital accumulated by surgeons on the job may also be specific to the tasks being performed, as opposed to being specific to the firm. In this context, I use the term "task" to connote a specific procedure. A cardiac surgeon may perform multiple tasks

\footnotetext{
${ }^{6}$ Refer to Hirshfeld et al (1998) for the complete statement of clinical competence released by the American College of Cardiology.
} 
within a hospital: she may perform CABG surgeries and she may also perform other cardiac procedures (e.g. repair of heart valves, heart transplants etc.). In such a situation, some part of the human capital may go unused when the surgeon switches tasks (either within the hospital or across hospitals). Whether surgeon learning transfers across tasks (procedures) depends on the extent to which the skills (of the surgeon or the surgical team) needed to perform these procedures overlap.

\subsection{Volume Outcome Studies in Healthcare}

The second stream of research relevant to this study encompasses papers in the medical and health economics literatures that document a correlation between procedure volume and outcomes at the firm (hospital) and individual (surgeon) levels. While it is difficult to compare findings across studies because of differences in data, disease categories studied and methodology, the general consensus among researchers seems to be that there is a positive relationship between procedure volume (measured at the level of the hospital or the individual surgeon) and provider quality, as measured by patient outcomes. ${ }^{7}$

However, few studies attempt to translate this correlation into a well established causal relationship between procedure volume and outcome. The literature offers two competing hypotheses, with contrasting causal and policy implications that could underlie this observed relationship. The first hypothesis is the "learning-by-doing" or the "practice-makes-perfect" hypothesis. This hypothesis is built on the notion that increased experience results in more finely developed skills which in turn lead to better outcomes. The second hypothesis is the "selective referral" hypothesis, which postulates that the observed relationship is due to a referral system that directs more patients to high quality providers.

The need to unambiguously distinguish between these two potential explanations arises from the fact that they have contrary implications for policy. "Learning-by-doing" is often used as an argument in favor of increased concentration among providers, whereas regionalizing procedures in the face of "selective referral" only leads to reduced competition, without any improvement in outcomes.

\footnotetext{
7 See Luft et al (1990) for a comprehensive review of volume-outcome studies, and Halm et al (2002) for a review of volume-outcome studies related to CABG.
} 
A few recent studies (Gowrisankaran, Town and Ho (2006), Picone, Trogdon and Trollis (2005)) use predicted volume as an instrument for actual procedure volume (at the hospital level), where predicted volume is estimated from a multinomial hospital choice model based on distance and basic hospital characteristics. The identification in these models comes from the fact that the location of patients relative to hospitals is a key determinant of hospital volume and is assumed to be exogenous to outcomes. These studies conclude in the favor of a strong learning-by-doing effect for hospitals performing cardiac procedures. While working with physician level data (as this paper does), this instrument is harder to implement because one needs to sort out the patient's choice of a hospital from her choice of a physician. Further, these studies cannot test for the presence of any aspects of specificity in learning-by-doing.

Analyses of volume-outcome effects using data at the surgeon level have tended to be largely correlational - i.e., these studies assume the presence of a positive correlation between provider volume and outcomes as indicative of a learning-by-doing effect. Examples of such studies include Hannan et al (1991) and Hughes et al (1987). Failure to account for selective referral in these studies may bias estimated effects of volume on outcome.

A further problem with correlational studies (that use OLS regression models of patient outcome on provider volume) is that one cannot assign a sign to the direction of the bias on the volume coefficient. The presence of selective referral should serve to make the OLS estimate larger in absolute value when compared to the IV estimate which parcels out this effect. However, if patients who are attracted to high quality surgeons are more ill in ways that are unobservable, it could lead to an increase in bad outcomes for the high quality surgeons, and result in OLS coefficients underestimating the true effect of learning-by-doing (in absolute terms). The only way to determine the direction of bias is by comparing OLS estimates with those obtained by IV regression. Section 6 presents results from such a comparison.

Huckman and Pisano (2006) were the first to examine the important question of firmspecificity of performance by using data on cardiac surgeons in the state of Pennsylvania, from 1994-1995. In particular, they look at whether a surgeon's experience (measured by procedure volume) at one hospital translates into better outcomes for her patients at other 
hospitals she operates in. Based on their specifications (which do not account explicitly for endogeneity of surgeon volume), they find a strong learning-by-doing effect and evidence to support firm-specificity of surgeon performance. While the focus of this study is to document the presence of learning effects among surgeons using robust empirical methods, the study setting allows me to make some inferences about the specificity of these effects as well.

In comparison to prior research, the primary contributions of this study are the following. First, I am able to establish a causal link between patient outcomes and provider experience (at the surgeon level) by using an instrumental variables technique. I am able to expand the scale and scope of existing studies by using detailed micro-level data over a lengthy study period (1998-2006). Finally, the basic idea underlying the instrument, that of exitor behavior affecting incumbents, is applicable in other settings: for example, one can examine the effects of a firm closure on other firms in a market. The study thus makes a useful contribution to the applied econometrics literature as well.

\section{Data and Research Setting}

\subsection{Selecting a Candidate Procedure}

I study the impact of learning-by-doing on quality for surgeons who perform Coronary Artery Bypass Grafts (CABG). Developed in the late $1960 s^{8}$, CABG is a risky and invasive surgical procedure that is normally performed on patients with severe or multiple narrowing of the coronary arteries. It is one of the ways ${ }^{9}$ in which Coronary Artery Disease, one of the leading causes of death in the $\mathrm{US}^{10}$, is treated. The procedure involves bypassing a blocked (or narrowed) segment of a heart artery by using a graft from the arm, leg or chest. Hospitals typically have dedicated operating rooms, fitted with specialized equipment and manned by dedicated technicians, in which the procedure is performed.

The referral process for CABG normally works as follows: a patient experiencing chest pains or shortness of breath starts by visiting a primary care physician who may then refer her to a cardiologist for further treatment and evaluation. The cardiologist evaluates the patient's

\footnotetext{
8 Source: Website of the American Heart Association

${ }_{9}$ Other treatments include medication and angioplasty

10 Source: National Center for Health Statistics, <http://www.cdc.gov/nchs/fastats/lcod.htm>
} 
medical history and symptoms and may perform a cardiac catheterization, a procedure that indicates how well blood is flowing through the vessels that supply the heart muscle. If the catheterization shows abnormal results, the patient is treated according to the extent of blockage in the arteries. Mild to medium blockages are treated using medication or angioplasty $^{11}$, while severe cases are referred to a surgeon for bypass surgery.

There are multiple reasons why CABG was selected as a candidate procedure for this study. First, it is a procedure that can be performed only by highly trained and specialized surgeons whose abilities are perceived as being crucial to the quality of care. Given the key role played by the surgeon, it is important to study the factors that affect surgeon performance. Second, CABG is a fairly common procedure with over 470,000 surgeries being performed in the US in $2004 .{ }^{12}$ It accounts for $\sim 4-5 \%$ of total health expenditure in the US, ${ }^{13}$ and is hence important in its own right. Third, the procedure has been extensively studied in the health economics literature with the result that there is a commonly accepted and readily available measure of outcomes: in-hospital mortality. ${ }^{14}$

Finally, since CABG is performed by surgical specialists, it is likely that a sizeable proportion of patients are referred to the appropriate hospital or surgeon (by their cardiologist) on the basis of provider quality - implying that "selective referral" could play an important role. Therefore, it becomes all the more important to not rely only on correlational studies of volume-outcome while estimating learning-by-doing effects.

\subsection{Data}

The primary dataset for this study comes from the Hospital Inpatient Data Files provided by the Florida Agency for Health Care Administration (AHCA) for the years 1998-2006. This data is comparable to patient level discharge data provided by the Health Care Utilization Project (HCUP) and the California Office of Statewide Health Planning and Development (OSHPD). Specifically, AHCA provides information about each discharge including the

\footnotetext{
11 This procedure is performed by an interventional cardiologist.

12 Source: 2004 National Hospital Discharge Survey

13 Ibid.

${ }^{14}$ An alternate measure of mortality used by some volume-outcome studies is 30-day mortality, defined as death occurring within 30 days of admission. The Florida AHCA data only identifies in-hospital mortality, while Medicare data files (which report 30-day mortality rates) typically do not include physician identifiers. So, I proceed with in-hospital mortality as my measure of patient outcome.
} 
hospital, physical and demographic characteristics of the patient (e.g. age, sex, payer information), and a comprehensive list of primary and secondary diagnoses. In addition, the data identify the license number of the operating surgeon, enabling me to track procedure volume of individual surgeons over a nine year time frame.

I also make use of a secondary dataset that provides me with information on characteristics of each surgeon present in the data. I obtain detailed information about each surgeon's training (e.g. medical school/residency program trained at, year of graduation) and draw inferences about the physician's age by linking the license number to an online database provided by the Florida Department of Health. ${ }^{15}$ To protect confidentiality, I do not present any physician-specific information.

I restrict attention to surgeons who appear more than once in the panel, and perform at least 5 procedures annually on average in order to exclude the effects arising from unrepresentative surgeons, e.g. an Emergency Room surgeon who may perform the occasional CABG surgery. I also exclude hospitals that appear in the bottom one-half percentile of the distribution of hospital procedure volume. The empirical results are robust to these sample restrictions.

\section{Using Surgeon Exit to Identify Exogenous Shocks to Procedure Volume}

This paper uses an instrumental variables approach to determine the extent to which increased procedure volume for surgeons translates into better outcomes for their patients. An ideal instrumental variable in this case should have the following properties: it should help explain variation in surgeon procedure volume (the endogenous predictor), and have no causal relationship with surgeon quality except through its effect on procedure volume. One can argue that concern about "selective referral" is mitigated at the surgeon level - this would hold true if patients only choose hospitals (and not individual surgeons) based on quality. However, to the extent that patients are typically referred to providers by other

\footnotetext{
15 This information is available at <http://ww2.doh.state.fl.us/irm00praes/praslist.asp >
} 
physicians $^{16}$ for procedures like the one studied in this paper (CABG), there is a strong possibility that higher quality surgeons attract more patients.

This paper proposes the use of surgeon exit as an exogenous identifier. I use the term "exit" to refer to an instance where a surgeon stops performing cardiac surgeries in Florida. ${ }^{17}$ Since a surgeon may exit the data for a variety of reasons (retirement, death, termination of employment, or relocation to a different state) some of which may confound identification, I use data on the surgeon's age to make an inference about the cause of exit and restrict the set of exiting surgeons accordingly. The rationale behind using surgeon exit as an identifier is as follows: once a surgeon exits a hospital for exogenous reasons, her procedure volume gets redistributed among non-exiting surgeons at the hospital, giving their procedure volumes a positive shock. If this shock to surgeon volume is not correlated with unobservable determinants of changes in surgeon quality, the use of exit as an identifier is valid. The instrumental variable used in the regressions is defined as a function of the volume of the exiting surgeon(s). I first provide a formal definition of the instrument before discussing some of the underlying identifying assumptions in detail.

\subsection{Defining the Instrument}

I identify surgeon exit in the data as follows: a surgeon exits a hospital if she stops performing cardiac procedures across all hospitals she was operating in. ${ }^{18} \mathrm{I}$ further restrict the set of exitors to surgeons aged 55 and over. ${ }^{19}$ Doing so increases the probability that a surgeon exited the data because she was retiring and mitigates concerns about endogeneity of exit. Even though most of the analysis focuses on CABG procedures, I consider all cardiac procedures (which include some non-CABG procedures, such as heart transplants, valve repairs etc) while identifying exiting surgeons. This is because the data contains some

\footnotetext{
${ }^{16}$ A patient first visits a cardiologist who may then refer her to a cardiac surgeon. . The data does not contain information on who provides the referral to the patient.

${ }^{17}$ I consider a surgeon to have exited when she stops performing cardiac procedures across all hospitals in Florida. I use this definition in order to rule out cases where a surgeon may exit a particular hospital but enter a nearby hospital, thereby taking patients with her.

${ }^{18}$ In a majority of cases, a surgeon exits all hospitals simultaneously and that year is taken to be the year of exit. In a few instances, a surgeon who works across multiple hospitals may exit one hospital but continue working in another. In such cases, I consider the surgeon to have exited only when she stops performing procedures altogether, and the latter year is taken as the year of exit from the data.

19 The data on surgeon characteristics does not contain the age of the surgeon, but does contain the year in which the surgeon graduated from medical school. I infer the surgeon's age using this information.
} 
cardiac surgeons who stop performing CABG procedures, but continue performing other types of cardiac surgeries. Since these surgeons are still active, and can potentially perform CABG procedures, I exclude them from the set of exiting surgeons. While most surgeons stop performing all types of cardiac procedures when they stop operating, I identify about 11 surgeons in the data who follow the above pattern, i.e. stop performing CABG procedures but are active in other cardiac procedures. The empirical results are robust to excluding these surgeons (and their patients) from the estimation sample. In section 6.5, I test the robustness of the empirical results by making other changes to the way exit is defined, and find little change in the conclusions.

The volume of the exiting surgeon is simply calculated as the number of CABG procedures performed by the surgeon in year $t-1$, where $t$ denotes year of exit. I assume that the impact of surgeon exit is felt on staying surgeon CABG procedure volumes for one year, i.e. if a surgeon exits in year $t$, then existing surgeons in a hospital experience an exogenous shock to their CABG procedure volumes in year $t$ only. The timing of the model works as follows: if a surgeon exits (i.e. stops performing procedures) in year $t$, the non-exiting surgeons at that hospital experience a positive shock to $C A B G$ procedure volume in year $t$. This volume shock translates into better patient outcomes for these surgeons in year $t+1$.

While one can use the data to identify instances of surgeon exit, there is no way of using the data to determine how exit volume ${ }^{20}$ is allocated among staying surgeons. There are many ways in which patients who would have visited the exiting surgeon may be redistributed across non-exiting surgeons. I discuss two different methods of allocating exit volume across surgeons and test my main specifications under both scenarios.

Under the first allocation rule, CABG patients of the exiting surgeon are assumed to be allocated equally among all the remaining surgeons at the hospital. The instrument is then computed as the sum of the $\mathrm{CABG}$ procedure volumes of all exiting surgeons in that hospital. In other words, all surgeons working at a hospital face the same shock to volume

${ }^{20}$ I use the term exit volume to refer to the number of CABG procedures performed by an (exiting) surgeon at a hospital the year before exit. 
(equal to the above sum of exit volumes of individual physicians), irrespective of their shares prior exit. $^{21}$

One demerit of the instrument as defined above is that it exhibits no variation across surgeons within a hospital in a particular year. In other words, a high volume surgeon stands to gain as much from exit as a low volume surgeon. Any attempts to apportion exit procedure volume in proportion to the current procedure volume shares of surgeons in a hospital run the risk of endogeneity.

The second allocation rule that I use leads to variation in the instrument across surgeons within a hospital without running the risk of endogeneity. Under this rule, I assign exit volume to each staying surgeon on the basis of the extent of patient zip code overlap with the exiting surgeon. To illustrate the methodology, consider a hospital with three practicing surgeons in year $t-1$, one of whom (surgeon A) exits in year $t$. Table A1 presents the breakdown of the exiting surgeon's CABG procedure volume by the zip code of the patients treated. Rows 2 and 3 of Table A1 present the distribution of patients across those zip codes operated upon by the other (non-exiting) surgeons in the hospital. ${ }^{22}$

Table A1. Zip code breakdown of surgeon CABG procedure volume, year $t-1$

\begin{tabular}{|l|c|c|c|}
\hline & \multicolumn{3}{|c|}{ Number of CABG patients treated by surgeon in zip code, year t-1 } \\
\cline { 2 - 4 } & $\mathbf{6 0 2 0 1}$ & $\mathbf{6 0 0 3 1}$ & $\mathbf{6 0 1 1 0}$ \\
\hline Surgeon A & 10 & 8 & 6 \\
\hline Surgeon B & 3 & 5 & 0 \\
\hline Surgeon C & 0 & 1 & 0 \\
\hline
\end{tabular}

21 This is equivalent to using an indicator for exit (set to 1 if a hospital has at least one physician who exits that year) as the instrument.

${ }^{22}$ Note that the non-exiting surgeons may draw patients from other zip codes as well - this table lists patient zip codes of the exiting surgeon only. 
Since surgeon A exits the data in year $t$, her CABG procedure volume in year $t-1$ is assigned to the other surgeons in the hospital in year $t$. Table A2 presents the allocation of A's exit volume to the non-exiting surgeons in the year post exit. Note that in Column 1, surgeon $\mathrm{C}$ is allocated no patients from zip code 60201 as she does not treat any CABG patients from that location. As a result, the zip code-level exit volume of 10 patients is entirely allocated to surgeon B. In Column 2, the zip code-level exit volume (of 8 patients) is equally divided amongst both staying surgeons as they both treat CABG patients from that zip code in $t-1$. Note that division of exit volume in this zip code is independent of surgeon market share in CABG (in that zip code) - this allocation rule tries to ensure that the additional CABG procedure experience gained by a surgeon from exit is independent of her current CABG procedure volume, which may reflect unobserved components of quality. Finally, patients in non-overlapping zip codes (zip code 60110 in the example above) are allocated equally across all non-exiting surgeons.

Table A2. Calculating exogenous volume shock, year $t$

\begin{tabular}{|l|c|c|c|c|}
\hline & \multicolumn{4}{|c|}{ Allocation of exit volume, year t } \\
\cline { 2 - 5 } & $\mathbf{6 0 2 0 1}$ & $\mathbf{6 0 0 3 1}$ & $\mathbf{6 0 1 1 0}$ & Total \\
\hline Surgeon B & 10 & 4 & 3 & 17 \\
\hline Surgeon C & 0 & 4 & 3 & 7 \\
\hline
\end{tabular}

In Section 6 of this paper, I present results using both allocation rules side-by-side for comparison.

\subsection{Why is Surgeon Exit a Plausible Instrument?}

I now discuss some of the underlying assumptions in using surgeon exit to identify exogenous changes in surgeon procedure volumes. I test the validity of these assumptions using the data, and include these results in a later section.

The correlation between the procedure volumes of staying surgeons and the volume of exiting surgeons (i.e. the relevance of the instrument) could be mitigated under some conditions. The first possibility is that the hospital hires new surgeons who take over the 
caseload of exiting surgeons. In that case, the procedure volume of non-exiting surgeons is unaffected by exit. However, the data show that surgeon exit is accompanied by entry (the same year) in only $9 \%$ of the cases. Further, an entering surgeon performs only $21 \mathrm{CABG}$ procedures at a hospital in the year of entry, compared to an exiting surgeon who performs 49 CABG procedures on average. Taken together, these facts imply that entry of new surgeons should not affect instrument relevance significantly.

The second possibility is that the procedure volume of the exiting surgeon is "lost" to the hospital, i.e. patients who would have visited the exiting surgeon now choose a different hospital instead of visiting another surgeon in the same hospital. However, the data indicate that there is very little variation in hospital CABG procedure volume over time; hospital CABG procedure volume decreases by $0.8 \%$ the year of exit, compared to a $1 \%$ average annual increase over all years. This implies that surgeon exit does not lead to a significant decrease in a hospital's annual CABG procedure volume.

I now turn to the question of instrument exogeneity. The main specifications include surgeon fixed effects implying that the dependent variable is the change in quality of the surgeon. The identifying assumption I make here is that the cause of surgeon exit is not directly related to changes in (non-exiting) surgeon quality. This assumption ensures that the instrument (which is a function of exiting surgeon volume) is uncorrelated with unobservable determinants of changes in staying surgeon quality. I test this assumption using the data and provide the details of this test in Section 6.

\section{A Robust Empirical Model of Learning-by-Doing}

\subsection{Instrumenting for Total Surgeon Experience}

In order to estimate the extent of surgeon learning-by-doing, I model surgeon quality as a function of various characteristics of the patient being treated, of the hospital she is treated at, and of the surgeon performing the procedure, including surgeon experience. Specifically, I estimate an instrumental variables regression where observations are at the level of the patient and the endogenous predictor, surgeon experience, is instrumented for. I present here the main specifications, in the form of a two-stage least squares regression in order to 
aid exposition. Equations (1.0) and (1.1) represent the first ${ }^{23}$ and second stages, respectively, in the instrumental variables estimation procedure. The variables and notation are explained in detail below, starting with the second stage regression equation. In all equations, $i$ indexes the patient, $b$ indexes the hospital, $p$ indexes the surgeon and $t$ indexes the time period of observation.

$$
\begin{aligned}
(\text { Physvol })_{p, t-1} & =\alpha_{0}+\alpha_{1} *(\text { Exitvol })_{p, t-2}+\alpha_{2} * X_{i, p, h, t}+\alpha_{3} * \theta_{p}+\alpha_{4} * \mu_{h} \\
& +\alpha_{5} *(\text { Year })_{t}+v_{p, t-1} \\
(\text { Outcome })_{i, p, h, t} & =\beta_{0}+\beta_{1} *(\text { Phŷsvol })_{p, t-1}+\beta_{2} * X_{i, p, h, t}+\beta_{3} * \theta_{p}+\beta_{4} * \mu_{h} \\
& +\beta_{5} *(\text { Year })_{t}+\varepsilon_{i, p, h, t}
\end{aligned}
$$

Second Stage Regression

Dependent variable: The dependent variable in the second stage regression is a measure of surgeon quality. Since analyses are conducted at the level of the patient, I use in-hospital patient mortality as the primary measure for surgeon quality. The main advantage of using in-hospital mortality as a measure of outcome is that there is very little chance of miscoding. In addition, there is sufficient variation in outcomes across surgeons and hospitals which allows me to estimate learning effects with precision. However, it may not completely reflect the health status of the patient post surgery. The dependent variable Outcome $e_{i, p, b, t}$ is a binary variable that is set to one if patient $i$ died as a result of a CABG procedure performed by surgeon $p$ in hospital $h$ at time $t$.

Independent variables - surgeon experience: The primary predictor of interest measures the experience of the surgeon performing the procedure. I proxy for surgeon experience by the total number of CABG procedures performed by the surgeon the previous year, Physvol $_{p, t-1}$. This measure is aggregated across all hospitals the surgeon operates at. In eq.

23 The unit of observation for the first stage regression is the patient (as in the second stage). However, I have suppressed the patient index $i$ in the notation for ease of exposition. 
(1.1), Phyŝvol ${ }_{p, t-1}$ denotes the predicted value from the first stage regression, eq. (1.0). The coefficient $\beta_{1}$ tells us the effect of surgeon experience on outcomes, purged of any possible biases arising from endogeneity. A negative sign on $\beta_{1}$ will act as evidence in favor of the learning-by-doing hypothesis. I let surgeon volume enter the specification in a linear fashion above. $^{24}$

While prior theoretical and empirical research on learning-by-doing model experience as having a cumulative effect, I use recent volume to measure surgeon experience mainly because I observe cumulative volume only for a subset of surgeons in the data. ${ }^{25}$ The concern over using recent procedure volume instead of cumulative procedure volume is mitigated to an extent by recent research studies (Gowrisankaran, Town and Ho (2006), Gaynor, Seider and Vogt (2005)) that find a significant amount of organizational forgetting among hospitals performing CABG procedures. This implies that experience from the immediate past has a greater impact on outcomes when compared to experience from further before. As a robustness check, I estimate the model using the number of procedures performed by the surgeon in the last two years as a proxy for surgeon experience. I also repeat the analysis on a sample that contains only those surgeons who finish their residency training in 1998 or later. In this specification, I use cumulative volume as the proxy for surgeon experience.

Independent variables - surgeon characteristics: In order to isolate the effect of surgeon experience on outcomes, I control for other characteristics of the surgeon that determine quality. In the main specifications, I do this by including a vector of surgeon fixed effects $\left(\boldsymbol{\theta}_{F}\right)$ in the regression that account for the effect of time-invariant surgeon characteristics (e.g. sex, training etc. and unobservables that are fixed with time) on patient outcomes. I also run a specification that excludes surgeon fixed effects; ${ }^{26}$ in this model, I control for the

\footnotetext{
${ }^{24}$ In an alternate specification, I used the square root of procedure volume as the measure for volume in order to incorporate nonlinearity. The linear specification was found to have a better fit (in terms of $\mathrm{R}^{2}$ ) so I proceed with that for the rest of the specifications. Models using the square root of volume yielded similar conclusions. ${ }^{25}$ Specifically, the data allow me to track all procedures only for surgeons who finish their residency training in 1998 or later.

${ }^{26}$ I do this mainly to facilitate comparison with earlier surgeon level volume outcome studies that do not include surgeon fixed effects in their specifications.
} 
following surgeon characteristics: age, sex and whether the surgeon trained at a foreign medical school.

Independent variables - hospital fixed effects: I include a vector of hospital fixed effects $\left(\boldsymbol{\mu}_{\boldsymbol{r}}\right)$ to control for systematic intrinsic quality differences across hospitals. ${ }^{27}$

Independent variables - patient characteristics: The vector $\mathrm{X}_{i, p, h, t}$ includes patient characteristics (e.g. the number of co-morbidities, patient age, sex, an indicator for whether the patient has had a prior CABG), all of which are expected to have an impact on patient mortality. The patient characteristics I include in the regression are: patient age categories, sex, the Charlson co-morbidity index ${ }^{28}$, concurrent angioplasty, cardiogenic shock, prior CABG surgery, congestive heart failure, hypertension and an indicator for a heart attack. I also include an indicator for whether the patient was admitted via the Emergency Room, as such patients usually tend to be sicker in unobserved ways. All specifications also contain year indicators to control for the effect on outcomes of changes in technology that are not captured by other predictors.

\section{First Stage Regression}

In the first stage regression (eq. (1.0)), surgeon volume is estimated as a function of the instrument and all exogenous predictors from the second stage. Note that a staying surgeon's procedure volume in year $t-1$ is affected by surgeons who exit in year $t-1$. Thus, the instrument allocates exiting surgeons' procedure volume in year $t$-2 to staying surgeons in year $t$-1. I use the sum of the exit volumes allocated to the staying surgeon across all hospitals to instrument for past procedure volume of the staying surgeon. The effect of exit on the procedure volume of staying surgeons is assumed to last for a year. Based on the discussion in Section 4, the coefficient $\alpha_{1}$ is expected to have a positive sign in eq. (1.0).

\footnotetext{
${ }^{27}$ Note that hospital fixed effects are not perfectly collinear with surgeon fixed effects as surgeons may work across multiple hospitals in the same year.

28 The Charlson co-morbidity index reflects the cumulative increased likelihood of one year mortality arising from different categories of co-morbidity such as cancer, diabetes, AIDS etc. The higher the score, the worse the condition of the patient.
} 


\subsection{Instrumenting for Specific Aspects of Surgeon Experience}

The regression equations for exploring specificity of surgeon experience are set up in a similar manner. I estimate a patient-level instrumental variables regression where the dependent variable is, as before, a measure of surgeon quality (patient outcome). The key difference is that I now use a hospital-specific measure of surgeon experience as the primary predictor. The variable Physhospvol ${ }_{p, h,-1} \quad$ measures the CABG procedure volume of surgeon $p$ at hospital $b$ in the year $t-1$, while Physhospvol ${ }_{p, h, h-1} \quad$ measures the CABG procedure volume of the same surgeon across all other hospitals (apart from hospital b) in $t-1$. In Eq. (1.4), the variables Physhospvol ${ }_{p, h, t-1}$ and Physhôspvol ${ }_{p,-h, t-1} \quad$ refer to the predicted values of these variables from the first stage regressions.

$$
\begin{aligned}
& \text { (Physhospvol }_{p, h, t-1}=\alpha_{0}+\alpha_{1} *(\text { Exitvol })_{p, h, t-2}+\alpha_{2} *(\text { Exitvol })_{p,-h, t-2}+\alpha_{3} * X_{i, p, h, t} \\
& +\alpha_{4} * \theta_{p}+\alpha_{5} * \mu_{h}+\alpha_{6} *(\text { Year })_{t}+v_{p, h, t-1} \\
& \text { (Physhospvol }_{p,-h, t-1}=\gamma_{0}+\gamma_{1} *(\text { Exitvol })_{p, h, t-2}+\gamma_{2} *(\text { Exitvol })_{p,-h, t-2}+\gamma_{3} * X_{i, p, h, t} \\
& +\gamma_{4} * \theta_{p}+\gamma_{5} * \mu_{h}+\gamma_{6} *(\text { Year })_{t}+\eta_{p,-h, t-1}
\end{aligned}
$$

$$
\begin{aligned}
(\text { Outcome })_{i, p, h, t} & =\beta_{0}+\beta_{1} *(\text { Physhôspvol })_{p, h, t-1}+\beta_{2} *(\text { Physhôspvol })_{p,-h, t-1}+\beta_{3} * X_{i, p, h, t} \\
& +\beta_{4} * \theta_{p}+\beta_{5} * \mu_{h}+\beta_{6} *(\text { Year })_{t}+\varepsilon_{i, p, h, t}
\end{aligned}
$$

Correspondingly, I use hospital-specific instruments for surgeon procedure volume in the first stage regressions (1.2) and (1.3). Exitvol ${ }_{p, h, t-2}$ is calculated as the exit volume allocated to surgeon $p$ at hospital $h$ in $t-2$, while Exitvol $_{p,-h, t-2}$ is calculated as the sum of exit volumes allocated to surgeon $p$ across all other hospitals (other than $b$ ) in $t-2$.

If human capital acquired by learning-by-doing were firm-specific, one would expect additional surgeon experience to have a greater benefit on patient outcomes at the hospital 
where the experience was gained. In other words, if $\beta_{1}$ and $\beta_{2}$ are both negative, and furthermore, $\beta_{2}$ is smaller in absolute value than $\beta_{1}$, the implication is that procedure volume at other hospitals does impact surgeon quality at the hospital under consideration, but not as much as procedure volume at the same hospital. This would be evidence in support of firmspecificity. A stronger form of firm specificity, in which experience is completely nontransferable across firms, would have $\beta_{2}$ equal to zero (or statistically indistinguishable from zero). On the other hand, if performing additional procedures (irrespective of hospital) adds to a surgeon's general human capital, one would expect $\beta_{1}$ and $\beta_{2}$ to be statistically indistinguishable from each other.

I test for task-specificity of surgeon human capital by using a specification similar to the one described above. Instead of using hospital-specific measures of surgeon volume, I now use task-specific measures. Specifically, I divide the total number of cardiac procedures performed by each surgeon into the number of $C A B G$ and the number of non-CABG procedures. I construct analogous versions of the instrument and compare the coefficients on the volume terms to make inferences on task-specificity of human capital.

\section{Results}

Before discussing the regression results, I present some patterns in the raw data. The study uses data on a total of 313 CABG surgeons working at 74 hospitals in Florida over 9 years, with a total volume of 220,652 procedures. The number of surgeons in each year increases from 231 in 1998 to 251 in 2006, while the number of hospitals increases from 58 to 74 over the same time period. Table 1 presents descriptive statistics of some of the key variables used in the specification. These statistics are calculated from patient-level data. The dependent variable, patient mortality, has a mean of $3.72 \%$ in the data, which is in line with mortality rates observed in other studies. The patient population is composed of a majority of males $(\sim 71 \%)$ who were over 65 years old on average. Around $6 \%$ of the population had had a previous CABG surgery.

The bottom panels of the table present surgeon and hospital characteristics. CABG surgeons in the data were overwhelmingly male $(96 \%)$ and a majority of them graduated from a US medical school $(\sim 78 \%)$. The median surgeon in the data graduated from medical school in 
1982. The average surgeon performs 184 cardiac procedures annually, across all hospitals. This number drops to 114 when we consider volume of CABG procedures. The average hospital employs around 6 surgeons. A surgeon performs CABG procedures across slightly more than 2 hospitals on average, and almost 50\% of surgeons work across multiple hospitals. In all, I record 41 instances where a surgeon exits the data. Overall, 224 nonexiting surgeons in the data are affected at some point in time by surgeon exit and experience a positive shock to their volumes.

\subsection{Do Surgeons Learn From Experience?}

Columns 1 and 2 of Table 2 contain results from OLS regression models that treat surgeon volume as exogenous) of patient mortality on lagged surgeon volumes. I present these in order to facilitate comparison with existing volume-outcome studies, and to demonstrate the need for instrumenting for surgeon volume. While the first column shows evidence for an inverse relationship between surgeon volume and patient mortality, this cannot be treated as evidence for learning-by-doing because this coefficient includes the influence of "selective referral". Moreover, the coefficient drops in magnitude (and becomes statistically insignificant) once surgeon fixed effects are included, implying that the negative coefficient was not a result of learning-by-doing but was being identified off differences across surgeons.

Table 3 presents the results from first-stage regressions of lagged surgeon CABG procedure volume (across all hospitals) on the instrument, along with all other exogenous predictors from Stage 2. Columns 1 and 2 present the results for specifications using the equal allocation instrument as the predictor, without and with surgeon fixed effects respectively. Specifications that do not include surgeon fixed effects include surgeon characteristics (surgeon age, sex etc) as controls. In both columns, the coefficient on the instrument is positive and highly significant indicating that exit volume faced by the surgeon is strongly correlated with actual procedure volume. In columns 3 and 4, I use the instrument constructed using zip-code based allocation and find similar results. Across all specifications, 
the F-statistic $^{29}$ for instrument significance is substantially larger than the typical recommended thresholds ${ }^{30}$, validating use of the instrument.

Columns 1 through 4 of Table 4 present results from specifications that estimate the extent of surgeon learning-by-doing using instrumental variables. As above, columns 1 and 2 present the results for specifications using the equal allocation instrument as the predictor, without and with surgeon fixed effects respectively. The specifications in the last two columns use the instrument constructed using the zip-code based allocation rule. The specifications estimated without surgeon fixed effects include a vector of surgeon characteristics in order to capture the effect of surgeon-specific factors on patient mortality.

The results in the table lend strong support to the learning-by-doing hypothesis: the coefficient on lagged surgeon procedure volume in column 1 is negative and significant at the 5\% level. The magnitude of the coefficient in column 1 implies that performing one additional CABG procedure in the previous year leads to a decline of .0051 percentage points in mortality. This represents a decrease of around $0.14 \%$ relative to the average value of mortality in the data (.0372), which is indicative of a strong learning-by-doing effect. Column 2 adds surgeon fixed effects to the model, implying that learning effects are now computed only using within-surgeon variation. The coefficient on lagged surgeon volume is still strongly significant $(p=.009)$, and the magnitude of the volume coefficient $(-5.93 \mathrm{E}-05)$ is similar to the one obtained earlier. When we use the zip-code based rule to construct the instrument, the results remain statistically significant and are slightly stronger in magnitude (columns 3 and 4). The coefficients imply a $0.17 \%-0.18 \%$ decrease in mortality for each additional CABG procedure performed by the surgeon in the previous year. While not of direct interest, the coefficients on the control variables (patient characteristics) are consistent with expectations.

The results of a Hausman test (not included here) reject equality between OLS and IV estimates. The coefficient on volume obtained from OLS regression is smaller in magnitude when compared to that obtained from the IV regressions. As discussed earlier, this implies that the type of patients attracted to high quality surgeons probably tend to be sicker in ways

\footnotetext{
${ }^{29}$ In the case of a single instrument, the F-statistic is simply the squared value of the t-statistic.

30 As a rule of thumb, Staiger and Stock (1997) recommend a first-stage F statistic of at least ten for an instrument not to be considered weak.
} 
that are unobservable. Overall, the IV results from all specifications presented in Table 4 provide strong evidence to support the presence of learning-by-doing in CABG surgeons.

\subsection{Testing the Identification Assumption}

Before proceeding with further specifications, I now test the main identification assumption behind using exit volume as an instrument, i.e. the assumption that exit volume is uncorrelated with unobserved determinants of changes in staying surgeon quality. I validate this assumption by testing if the amount of exit volume faced by a surgeon is determined by her quality in the previous period. This reduced form regression is performed at the level of the surgeon-year and uses the instrument as the dependent variable and the lagged riskadjusted surgeon-level mortality rate, ${ }^{31}\left(\right.$ Mortrate $_{p, t-1} \quad$ as the primary predictor. I also include surgeon characteristics $\left(\psi_{p, t}\right)$ - age, sex, whether the surgeon is foreign trained and year and hospital fixed effects as controls.

$$
\begin{aligned}
(\text { Exitvol })_{p, t} & =\beta_{0}+\beta_{1} *(\text { Mortrate })_{p, t-1}+\beta_{2} * \psi_{p, t}+\beta_{3} * \lambda_{h} \\
& +\beta_{4} *(\text { Year })_{t}+\xi_{p, t}
\end{aligned}
$$

The results, reported in columns 1 and 2 of Table 5, indicate that the coefficient on the primary predictor, lagged surgeon quality, is statistically indistinguishable from zero, using either definition of the instrument. This suggests that the amount of exit volume faced by a surgeon is independent of her prior quality, and validates the main identification assumption in the paper.

\subsection{Does Experience Benefit All Surgeons Equally?}

The results presented in Table 4 are consistent with the learning-by-doing hypothesis but impose the restriction that the effect of experience on surgeon performance does not vary across surgeons. Table 6 presents results from specifications that relax this restriction. First,

\footnotetext{
${ }^{31}$ In order to compute risk adjusted mortality rate for each surgeon, I run a patient-level logit model where the dependent variable equals one if the patient died, and the predictors include all patient characteristics and a vector of year fixed effects. I then sum up the predicted probability of mortality for all patients across a surgeon and divide by the number of patients treated by that surgeon.
} 
in columns 1 and 3, ${ }^{32} \mathrm{I}$ include an interaction term in order to allow for a nonlinear effect of procedure volume on mortality. ${ }^{33}$ The coefficient on lagged surgeon procedure volume is statistically significant and negative, with a magnitude similar to the estimates obtained in Table 4. The coefficient on the interaction term, however, is positive and significant. These results indicate that high volume surgeons (defined as those performing 175 procedures a year or above) benefit less from additional experience (each additional procedure performed in the previous year leads to a $.08 \%-.10 \%$ drop in patient mortality) when compared to their counterparts who perform fewer procedures a year.

Another underlying source of heterogeneity that could affect the extent to which surgeon experience affects performance, is the age of the surgeon. I test for this possibility by interacting the lagged procedure volume of the surgeon with the number of years since the surgeon graduated from medical school. ${ }^{34}$ The coefficient on the interaction term (in columns 2 and 4) is positive, implying that older surgeons obtain a smaller benefit from additional procedure experience, although the net effect of experience is still beneficial even for surgeons who graduated from medical school more than 20 years earlier. ${ }^{35}$

\subsection{Is Experience Specific?}

Table 7 presents results from the models in Section 5.3 that tests for the firm- and taskspecificity of human capital acquired through learning-by-doing. The coefficients provide evidence in favor of some degree of specificity of human capital. In columns 1 and 3, the coefficient on own-hospital volume is negative and significant and much larger in magnitude than the coefficient on other-hospital volume, which is also negative but statistically significant only in Column 3 (the coefficient has $\mathrm{p}=.086$ in column 1). For both specifications, a t-test is able to reject equality of the coefficients on the two variables measuring procedure volume (at own and other hospitals), indicating that the benefits of procedure experience are somewhat (but not perfectly) portable across hospital settings. This

\footnotetext{
${ }^{32}$ The table contains results using both definitions of the instrument, as before. All specifications include surgeon fixed effects.

${ }^{33}$ I define a high volume surgeon as one who performs more than 175 CABG procedures a year

${ }^{34}$ I use the year of graduation from medical school as opposed to graduating from residency owing to the greater consistency of this measure in the data. Estimates using residency graduation year yielded similar conclusions.

${ }^{35}$ The slight decrease in the number of observations in columns 2 and 4 is caused by lack of data on surgeon graduation.
} 
result is slightly different from the findings of Huckman and Pisano (2006) who find that performance benefits of experience are restricted to the same hospital. While I find that experience gained by a surgeon aids her performance across hospitals, the benefit obtained from other-hospital experience is much smaller in comparison to that obtained from ownhospital experience. I believe that the difference in findings across the two studies probably arises from the instrumentation strategy used here. ${ }^{36}$

In Columns 2 and 4, I present results from the specification testing for task-specificity of human capital. The coefficients on both volume terms (CABG procedure volume and nonCABG procedure volume) are negative and statistically significant at the 5\% level. However, the $\mathrm{CABG}$ volume coefficient is much larger in magnitude (around 15 times as large). These estimates indicate that there is some benefit of performing non-CABG procedures on CABG outcomes, but the impact of this experience is smaller than the impact of experience performing CABG procedures. I interpret this as evidence in favor of some degree of taskspecificity of human capital. The main implication of this result is that there seems to be some economies of scope across procedures for surgeons. This provides one explanation as to why surgeons do not specialize in performing just one particular procedure.

\subsection{Robustness Checks}

I test the robustness of the estimates through various specification checks and sample restrictions. Table 8 contains results from these specifications. In all specifications, I focus on the coefficient of lagged surgeon volume which is the main coefficient of interest. I use the version of the instrument constructed using zip-code based allocation in all specifications reported in this table. In column 1, I test the sensitivity of the results to an alternate definition of the instrument. I relax the restriction on surgeon age used in the definition and designate all surgeons who stop performing procedures as exitors. This increases the number of exiting surgeons in the data to 72 . The coefficient on lagged surgeon volume is now smaller in magnitude, but still negative and statistically significant.

In columns 2 and 3, I address the concern about using recent procedure volume (as opposed to cumulative procedure volume) to proxy for surgeon experience. In column 2, I use the

\footnotetext{
${ }^{36}$ Huckman and Pisano (2006) do not employ instruments but use lagged surgeon Risk Adjusted Mortality Rate to account for surgeon quality
} 
CABG procedure volume of the surgeon over the last two years and in column 3, I use the cumulative $\mathrm{CABG}$ procedure volume as measures of experience. In both cases I calculate the instrument in an analogous manner. Since I observe cumulative experience only for surgeons who start practicing after 1998, I restrict the sample accordingly in column 3 . The coefficient on lagged surgeon procedure volume remains statistically significant and largely unchanged in magnitude (-5.48E-05) when I use the two-year measure instead of the prior year measure. When I restrict the sample to surgeons who start practicing in 1998 or later (in column 3), the coefficient on lagged procedure volume has the right sign (-2.87E-05) but is statistically insignificant. This is probably an artifact of the much smaller sample size in this specification.

Column 4 tests the sensitivity of the results to excluding all the control variables from the model. Finally, in column 5, I include surgeon-hospital interaction dummies in the regression instead of including them separately. The model is robust to these alternate specifications as well.

I also tested the robustness of the results to the sample restrictions imposed earlier, by including low volume hospitals and surgeons in the sample and found that the main conclusions were not affected. In summary, the results are quite robust to alternate specifications. The only situation in which we lose statistical significance is when the sample is restricted to surgeons who start practicing in 1998 or later. In all other models, our main conclusions remain unchanged.

A possible alternate explanation behind the results is that exiting surgeons chose patients from zip codes whose inhabitants were healthier in unobserved ways. When these surgeons exit, the staying surgeons seem to experience an increase in quality (caused by the rise in procedure volume) when, in reality, they are now operating on patients who are healthier. I address this concern in two ways. First, the data show that patients of exiting surgeons had an average Charlson co-morbidity index of .878 compared to patients of staying surgeons who had an average Charlson index of .886. Since the patients of exiting surgeons seem to be as healthy as the patients of staying surgeons in observable ways, it is reasonable to assume that they do not differ significantly in unobservable ways. Second, the estimates show that increased procedure experience benefits surgeons across hospitals (and thus, 
across zip codes) to some degree. This implies that the result is not driven by unobservable differences in patient health across zip codes.

\section{Concluding Remarks}

In this paper I examine the benefits of experience, one of the mechanisms through which individuals acquire (or maintain) competence in an organizational setting. Specifically, I study whether cardiac surgeons who perform more procedures experience an improvement in performance. In order to do so, I develop an instrumental variables estimation method that addresses the potential endogeneity of surgeon procedure volume. As my identification strategy, I consider exogenous shocks to the procedure volume of existing CABG surgeons in Florida caused by the exit of other surgeons from the same hospital. Using this instrument, I find evidence for a strong learning-by-doing effect for cardiac surgeons: an additional procedure a year leads to a reduction in patient mortality by $0.14 \%$. In addition, I find evidence in support of some degree of firm- and task-specificity of human capital accumulated by learning-by-doing.

While I believe that this study represents an improvement over prior research, it has its share of limitations, one of the main ones being that the effect of hospital procedure volume on outcomes is not modeled. Since physician and hospital services are co-located, one cannot sort out their separate effects so easily. While some of the positive benefits of hospital volume on outcomes are captured by surgeon volume, others may not be. For example, larger hospitals may have a broader range of specialists and thus have experience with more diseases or co-morbidities and may learn to manage these better, leading to an improvement in patient outcomes. To the extent that such effects are not captured by hospital fixed effects, our estimates of surgeon learning-by-doing may be biased. ${ }^{37}$

Another limitation pertains to the analysis of firm-specificity. The analysis assumes that the surgeon decision to operate across multiple hospitals is exogenous to her quality. This may not hold true if surgeons who split their time across hospitals are of, say, higher quality (and are hence able to attract patients across hospitals). In that case, the estimates from the

\footnotetext{
37 Studies that have tested for the effects of both surgeon and hospital volume (in a correlational manner, without factoring for possible endogeneity biases) have found surgeon volume to be a much stronger predictor of patient outcomes
} 
specifications in section 6.2 may be biased. A better strategy would be to instrument for the splitting decision. I leave this avenue open for further investigation.

A final limitation of the study is that CABG may be performed by teams consisting of two or more surgeons. Since the data only identifies the primary operating surgeon, I am unable to factor for the experience of other surgeons in the same surgical team who may have been involved in the procedure.

One of the questions that may arise about this study pertains to what exactly is being measured. Do the estimates reflect the core learning process of surgeons? Or do they represent the process by which surgeons maintain their skills, as opposed to learning new ones? The data does not allow me to disentangle these two effects. However, to the extent that surgeons perfect their procedural skills during (residency) training or the first couple of years of practice itself, most established surgeons can be thought of as already being on the "flat" portion of their learning curves. Maintaining proficiency of skills by ensuring an adequate volume of procedures remains a recognized concern of surgeons. This concern arises due to the deterioration of skills with lack of practice: a surgeon who has an opportunity to consistently perform procedures over time will be able to maintain her abilities and skill level better than an equally trained surgeon who performs only a handful. Thus, the estimates may well measure the degree of "not-forgetting" as opposed to "learning".

This study adds to the large and growing theoretical and empirical literature that analyzes learning-by-doing in a variety of settings and industries. While the unit of analysis in most of these studies is the firm, this paper is able to look at learning-by-doing at the level of the individual worker, mainly due to the availability of detailed data. This study is to be viewed as a first step towards understanding the mechanism by which workers acquire and maintain their skills in organizations. While this study documents the existence of learning-by-doing in individuals, the link between individual and organizational learning is yet to be made. 


\section{References}

Argote, Linda, Sara Beckman, and Dennis Epple. 1990. "The Persistence and Transfer of Learning in Industrial Settings”, Management Science, 36(2), 140-154

Argote, Linda, Daria Brooks, and Ray Regans. 2005. "Individual Experience and Experience Working Together: Predicting Learning Rates from Knowing Who Knows What and Knowing How to Work Together”, Management Science, 51(6), 869-881

Argote, Linda, Dennis Epple, Devadas Rao, and Kenneth Murphy. 1997. "The Acquisition and Depreciation of Knowledge in a Manufacturing Organization: Turnover and Plant Productivity", Working Paper, Carnegie Mellon University

Argote, Linda, Dennis Epple, and Devadas Rao, R. 1991. "Organizational Learning Curves: A Method for Investigating Intra-Plant Transfer of Knowledge Acquired Through Learningby-Doing", Organization Science, 2(1), 58-70

Argote, Linda, Dennis Epple, and Kenneth Murphy. 1996. "An Empirical Investigation of the Microstructure of Knowledge Acquisition and Transfer Through Learning-by-Doing", Operations Research, 44(1), 77-86

Becker, Gary. 1962. "Investment in Human Capital: A Theoretical Analysis", The Journal of Political Economy, 70(5), 9-49

Benkard, Lanier. 2000. "Learning and Forgetting: The Dynamics of Aircraft Production", American Economic Review, 90(4), 1034-1054

Besanko, David, Ulrich Doraszelski, Yaroslav Kryukov, and Mark Satterthwaite. 2007. "Learning-by-Doing, Organizational Forgetting, and Industry Dynamics", Working Paper, Northwestern University

Bessen, Jim. 1998. "Productivity Adjustments and Learning-by-Doing as Human Capital", Research on Innovation Working Paper

Darr, Eric, Linda Argote, and Dennis Epple. 1995. "The acquisition, transfer and depreciation of knowledge in service organizations: Productivity in franchises", Management Science, 41(11), 1750-1762

Delaney, Peter, Lynne Reder, James Staszewski, and Frank Ritter. 1998 "The StrategySpecific Nature of Improvement: The Power Law Applies by Strategy within Task", Psychological Science, 9, 1-7

Farley, Dean and Ronald Ozminkowski. 1992. "Volume Outcome Relationships and in hospital mortality: the effect of changes in volume over time" Medical Care, 30(1)

Gaynor, Martin, Harold Seider, and William Vogt. 2005 "The Volume-Outcome Effect, Scale Economies and Learning-by-Doing", American Economic Association Papers and Proceedings, May 2005, 243-247 
Gibbons, Robert. and Michael Waldman. 2004. "Task-Specific Human Capital”, American Economic Association Papers and Proceedings, May 2004, 203-208

Gowrisankaran, Gautam, Vivian Ho, and Robert Town. 2006 "Causality and the VolumeOutcome Relationship in surgery", NBER Working Paper

Halm Ethan, Clara Lee and Mark Chassin. 2002. "Is Volume related to outcome in health care? A systematic review and methodologic critique of the literature", Annals of Internal Medicine, 137(6)

Hamilton, Barton, and Vivian Hamilton. 1997 "Estimating Surgical Volume-Outcome Relationships Applying Survival Models: Accounting for Frailty and Hospital Fixed Effects", Health Economics, 6: 383-395

Hannan, E., O’Donnell, J., Kilburn, H, Bernard, H., and Yazici, A. 1989. "Investigation of the relationship between volume and mortality for surgical procedures performed in NY state hospitals", JAMA, 262(4), 503-510

Hannan, E., O’Donnell, J., Bernard, H., Lucacik, G. and Shields, E. 1991. “Coronary Artery Bypass Graft surgery: The relationship between in-hospital mortality rate and surgical volume after controlling for clinical risk factors", Medical Care, 29(11), 1094-1107

Hannan, E., O’Donnell, J., Bernard, H., Yazici, A, Lindsey, M.. and Shields, E. 1992. “ A longitudinal analysis of the relationship between in-hospital mortality in New York state and the volume of Abdominal Aortic Aneurysm surgeries performed", Health Services Research, 27(4)

Hatch, Nile and David Mowery. 1998. "Process Innovation and Learning-by-Doing in Semiconductor Manufacturing", Management Science, 44, 1461-1477

Hirshfeld, John, Stephen G. Ellis , David Faxon, et al. 1998. "Recommendations for the Assessment and Maintenance of Proficiency in Coronary Interventional Procedures", Journal of the American College of Cardiology, 31(3), 722-743

Ho, Vivian. 2002. "Learning and the evolution of medical technologies: The diffusion of Coronary Angioplasty" The Journal of Health Economics, 21(5), 873-885

Huckman, Robert and Gary Pisano. 2006. "The firm-specificity of individual performance: Evidence from cardiac surgery", Management Science, 52(4), 473-488

Hughes, Robert, Sandra Hunt, and Harold Luft. 1987. "Effects of Surgeon volume and hospital volume on quality of care in hospitals" Medical Care 25(6), 489-503

Jovanovic, Boyan. 1979. "Firm-Specific Capital and Turnover", The Journal of Political Economy, 87, 1246-1260

Killingsworth, Mark. 1982 "Learning-by-Doing and Investment in Training: A Synthesis of Two Rival Models of the Life Cycle", The Review of Economic Studies, 49(2), 263-271. 
Luft, Harold, Bunker, J.P., and Alain Enthoven. 1979. "Should operations be regionalized? The empirical relation between surgical volume and mortality". New England Journal of Medicine. 301(25), 1364-1369

Luft, Harold, Sandra Hunt, and Susan Maerki. 1987 "The Volume-Outcome Relationship: Practice-makes-Perfect or Selective-Referral Patterns?” Health Services Research 22(2), 157-182

Luft, Harold, Garnick, D., Mark, D., and McPhee, S. 1990. "Hospital Volume, Physician Volume and Patient Outcomes", Ann Arbor Health Administration Press

Nembhard, David, and Mustafa Uzumeri. 2000. "An Individual-Based Description of Learning within an Organization”, IEEE Transactions on Engineering Management, 47(3), 370378

Picone, Gabriel, Justin Trogdon, and James Jollis. 2005 "Hospital Volume and Quality of Care: practice-makes-perfect or selective referral", NBER Working Paper

Pisano, Gary, Bohmer, Richard, and Amy Edmondson. 2001 "Organizational Differences in Rates of Learning: Evidence from the Adoption of Minimally Invasive Cardiac Surgery”, Management Science, 47, 752-768

Shafer, Scott.M., David Nembhard, and Mustafa Uzumeri. 2001. "The Effects of Worker Learning, Forgetting and Heterogeneity on Assembly Line Productivity", Management Science, 47, 1639-1653

Staiger, Douglas and James Stock. 1997 "Instrumental Variables Regression with Weak Instruments”, Econometrica, 65(3), 557-586

Thompson, Peter. 2001. "How Much Did the Liberty Shipbuilders Learn? Evidence for an Old Case Study", Journal of Political Economy, 109(1), 103-37

Thompson, Peter. 2006. "How Much Did the Liberty Shipbuilders Forget?", Working Paper, Florida International University

Thornton, Rebecca, and Peter Thompson. 2001. "Learning from Experience and Learning from Others: An Exploration of Learning and Spillovers in Wartime Shipbuilding", American Economic Review, 91(5):1350-1368

Tsai, Alexander, Mark Votruba, Jon Bridges and Randall Cebul. 2006. "Overcoming Bias in Estimating the Volume-Outcome Relationship”, Health Services Research, 41(1), 252-264

Wright, Theodore. 1936. "Factors Affecting the Cost of Airplanes", Journal of the Aeronautical Sciences, 3(4): 122-128 
Table 1a. Summary Statistics for Key Patient Characteristics, 1998-2006 (Unit of Observation: patient. Number of Obs: 220652)

\begin{tabular}{|c|c|c|c|c|}
\hline & Mean & Std. Deviation & Minimum & Maximum \\
\hline \multicolumn{5}{|l|}{ Dependent Variable } \\
\hline Mortality Rate & 0.037 & 0.189 & 0 & 1 \\
\hline \multicolumn{5}{|c|}{ Patient Characteristics } \\
\hline Age & 67.46 & 10.66 & 10 & 95 \\
\hline$\%$ Female & 0.291 & 0.454 & 0 & 1 \\
\hline Charlson Index & 0.911 & 0.985 & 0 & 11 \\
\hline Prior CABG surgery & 0.054 & 0.227 & 0 & 1 \\
\hline Concurrent PTCA & 0.025 & 0.155 & 0 & 1 \\
\hline Heart Failure & 0.223 & 0.416 & 0 & 1 \\
\hline Cardiogenic shock & 0.022 & 0.148 & 0 & 1 \\
\hline Hypertension & 0.011 & 0.104 & 0 & 1 \\
\hline
\end{tabular}

Note: All statistics calculated using the patient as the unit of observation. Sample includes all patients undergoing CABG surgery in Florida from 1998-2006

Table 1b. Summary Statistics for Key Surgeon Characteristics, 1998-2006

(Unit of Observation: cardiac surgeon. Number of Obs: 313)

\begin{tabular}{|c|c|c|c|c|}
\hline & Mean & Std. Deviation & Minimum & Maximum \\
\hline \multicolumn{5}{|l|}{ Surgeon Characteristics } \\
\hline \% Foreign Medical School & 0.224 & 0.417 & 0 & 1 \\
\hline$\%$ Female & 0.042 & 0.199 & 0 & 1 \\
\hline Median Graduation Year: Med School & 1982 & --- & 1953 & 1997 \\
\hline Median Graduation Year: Residency & 1990 & --- & 1958 & 2005 \\
\hline \multicolumn{5}{|l|}{ Procedure Volume Measures } \\
\hline Annual Surgeon Volume: Cardiac Procedures & 184.09 & 108.03 & 6 & 549 \\
\hline Annual Surgeon Volume: CABG Procedures & 114.91 & 75.04 & 5 & 398 \\
\hline No. of Hospitals Operated in & 2.16 & 1.03 & 1 & 4 \\
\hline
\end{tabular}

Note: All statistics calculated using the surgeon as the unit of observation. The sample includes most cardiac surgeons (refer text for details on sample) performing surgeries in Florida from 1998-2006 
Table 2: Effect of Surgeon Experience on Patient Outcomes: OLS Estimates Dependent Variable: Did the Patient Die In-Hospital?

\begin{tabular}{|c|c|c|}
\hline \multirow[t]{2}{*}{ Surgeon CABG Volume, Prior Year } & $-3.76 \mathrm{E}-05^{* * *}$ & $-1.90 \mathrm{E}-05$ \\
\hline & 1.12E-05 & $1.75 E-05$ \\
\hline \multirow[t]{2}{*}{ Charlson Index } & $0.0023 * * *$ & $0.0023 * * *$ \\
\hline & $6.0 E-04$ & $6.0 E-04$ \\
\hline \multirow[t]{2}{*}{ Cardiogenic Shock } & $0.3195 * * *$ & $0.3175^{* * *}$ \\
\hline & $1.1 E-02$ & $1.1 E-02$ \\
\hline \multirow[t]{2}{*}{ Concurrent PTCA } & $0.0117^{* *}$ & $0.0107 * *$ \\
\hline & $4.0 E-03$ & $4.0 E-03$ \\
\hline \multirow[t]{2}{*}{ Hypertension } & $0.0207^{* * *}$ & $0.0213^{* * *}$ \\
\hline & $6.1 E-03$ & $6.1 E-03$ \\
\hline \multirow[t]{2}{*}{ Heart Failure } & $0.0275^{* * *}$ & $0.0270 * * *$ \\
\hline & 1.7E-03 & 1.7E-03 \\
\hline \multirow[t]{2}{*}{ Prior CABG } & $0.0259 * * *$ & $0.0255^{* * *}$ \\
\hline & $3.1 E-03$ & $3.1 E-03$ \\
\hline \multirow[t]{2}{*}{ Female } & $0.0132 * * *$ & $0.0129 * * *$ \\
\hline & $1.0 E-03$ & $1.0 E-03$ \\
\hline \multirow[t]{2}{*}{ Heart Attack } & $0.0056 * * *$ & $0.0054 * * *$ \\
\hline & $1.3 E-03$ & $1.3 E-03$ \\
\hline \multirow[t]{2}{*}{ Emergency Admission } & $0.0033^{* *}$ & $0.0034 * *$ \\
\hline & $1.2 E-03$ & $1.2 E-03$ \\
\hline Patient Age Categories & Y & Y \\
\hline Year Fixed Effects & $\mathrm{Y}$ & $\mathrm{Y}$ \\
\hline Hospital Fixed Effects & $\mathrm{Y}$ & $\mathrm{Y}$ \\
\hline Surgeon Characteristics & $\mathrm{Y}$ & $\mathrm{N}$ \\
\hline Surgeon Fixed Effects & $\mathrm{N}$ & $\mathrm{Y}$ \\
\hline
\end{tabular}

Number of Observations

$* * *$ signifies $\mathrm{p}<.001, * *$ signifies $\mathrm{p}<.01, *$ signifies $\mathrm{p}<.05$

Note: Columns 1 and 2 present results from specifications excluding and including surgeon fixed effects. Surgeon characteristics are included in Column 1 in order to control for underlying surgeon quality. Standard errors are robust and clustered by surgeon 
Table 3: First Stage (IV) Regression: Effect of Exit Volume on Surgeon Volume

Dependent Variable: Surgeon CABG Volume, Prior Year

\begin{tabular}{|c|c|c|c|c|}
\hline \multirow[b]{2}{*}{ Exit-related CABG Volume, Prior Year } & \multicolumn{2}{|c|}{ Equal Allocation } & \multicolumn{2}{|c|}{ Zip-code based Allocation } \\
\hline & $0.0377 * * *$ & $0.0536 * * *$ & $0.1490 * * *$ & $0.1281 * * *$ \\
\hline & 0.0054 & 0.0031 & 0.0262 & 0.0156 \\
\hline Patient Characteristics & Y & Y & $\mathrm{Y}$ & $\mathrm{Y}$ \\
\hline Year Fixed Effects & Y & $\mathrm{Y}$ & $\mathrm{Y}$ & $\mathrm{Y}$ \\
\hline Hospital Characteristics & $\mathrm{Y}$ & $\mathrm{Y}$ & $\mathrm{Y}$ & $\mathrm{Y}$ \\
\hline Hospital Fixed Effects & $\mathrm{Y}$ & $\mathrm{Y}$ & $\mathrm{Y}$ & $\mathrm{Y}$ \\
\hline Surgeon Characteristics & Y & $\mathrm{N}$ & $\mathrm{Y}$ & $\mathrm{N}$ \\
\hline Surgeon Fixed Effects & $\mathrm{N}$ & $\mathrm{Y}$ & $\mathrm{N}$ & $\mathrm{Y}$ \\
\hline Number of Observations & 189444 & 189466 & 189444 & 189466 \\
\hline \multicolumn{5}{|c|}{$* * *$ signifies $\mathrm{p}<.001, * *$ signifies $\mathrm{p}<.01, *$ signifies $\mathrm{p}<.05$} \\
\hline \multicolumn{5}{|c|}{$\begin{array}{l}\text { Note: Estimates are obtained off patient-level regressions using surgeon CABG volume in the prior year } \\
\text { as the dependent variable. Estimation sample includes CABG surgeons performing procedures in Florida } \\
\text { from } 1998 \text { to } 2006 \text {. Columns } 1 \text { and } 2 \text { present estimates for specifications with the instrument calculated } \\
\text { under the equal allocation rule. Columns } 3 \text { and } 4 \text { present similar estimates for the Zip-code based rule. } \\
\text { Columns } 1 \text { and } 3 \text { exclude surgeon fixed effects but include surgeon characteristics instead. Standard } \\
\text { errors are robust and clustered by surgeon. }\end{array}$} \\
\hline
\end{tabular}


Table 4: Effect of Surgeon Experience on Patient Outcomes: IV Estimates

Dependent Variable: Did the Patient Die In-Hospital?

\begin{tabular}{|c|c|c|c|c|}
\hline \multirow[b]{2}{*}{ Surgeon CABG Volume, Prior Year } & \multicolumn{2}{|c|}{ Equal Allocation } & \multicolumn{2}{|c|}{ Zip-code based Allocation } \\
\hline & $-5.11 \mathrm{E}-05^{*}$ & $-5.93 \mathrm{E}-05^{* *}$ & $-6.29 \mathrm{E}-05^{* * *}$ & $-6.83 \mathrm{E}-05^{* *}$ \\
\hline & $2.12 E-05$ & $2.27 E-05$ & $1.64 E-05$ & $2.18 E-05$ \\
\hline \multirow[t]{2}{*}{ Charlson Index } & $0.0023 * * *$ & $0.0023 * * *$ & $0.0023 * * *$ & $0.0026 * * *$ \\
\hline & $4.0 E-04$ & $4.0 E-04$ & $4.0 E-04$ & $5.0 E-04$ \\
\hline \multirow[t]{2}{*}{ Cardiogenic Shock } & $0.3193 * * *$ & $0.3175^{* * *}$ & $0.3191 * * *$ & $0.3189 * * *$ \\
\hline & $3.1 E-03$ & $2.9 E-03$ & $2.9 E-03$ & $3.0 E-03$ \\
\hline \multirow[t]{2}{*}{ Concurrent PTCA } & $0.0115 * * *$ & $0.0107 * * *$ & $0.0114 * * *$ & $0.0102 * * *$ \\
\hline & $3.0 E-03$ & $2.7 E-03$ & $2.7 E-03$ & $2.8 E-03$ \\
\hline \multirow[t]{2}{*}{ Hypertension } & $0.0203 * * *$ & $0.0213 * * *$ & $0.0200 * * *$ & $0.0215^{* * *}$ \\
\hline & $4.6 E-03$ & $4.0 E-03$ & $4.1 E-03$ & $4.2 E-03$ \\
\hline \multirow[t]{2}{*}{ Heart Failure } & $0.0274 * * *$ & $0.0270 * * *$ & $0.0273 * * *$ & $0.0270 * * *$ \\
\hline & $1.2 E-03$ & $1.0 E-03$ & $1.0 E-03$ & $1.1 E-03$ \\
\hline \multirow[t]{2}{*}{ Prior CABG } & $0.0262 * * *$ & $0.0255^{* * *}$ & $0.0265 * * *$ & $0.0258 * * *$ \\
\hline & $2.6 E-03$ & $1.9 E-03$ & $1.9 E-03$ & $1.9 E-03$ \\
\hline \multirow[t]{2}{*}{ Female } & $0.0131 * * *$ & $0.0129 * * *$ & $0.0131 * * *$ & $0.0129 * * *$ \\
\hline & $9.0 E-04$ & $9.0 E-04$ & $9.0 E-04$ & $1.0 E-03$ \\
\hline \multirow[t]{2}{*}{ Heart Attack } & $0.0053^{* *}$ & $0.0054 * * *$ & $0.0050 * * *$ & $0.0057 * * *$ \\
\hline & $2.0 E-03$ & $1.1 E-03$ & $1.1 E-03$ & $1.1 E-03$ \\
\hline \multirow[t]{2}{*}{ Emergency Admission } & $0.0032 *$ & $0.0033^{* *}$ & $0.0031^{* *}$ & $0.0027^{*}$ \\
\hline & $1.3 E-03$ & $1.1 E-03$ & $1.1 E-03$ & $1.1 E-03$ \\
\hline Patient Age Categories & Y & Y & Y & Y \\
\hline Year Fixed Effects & Y & Y & $Y$ & $\mathrm{Y}$ \\
\hline Hospital Characteristics & Y & Y & $\mathrm{Y}$ & $\mathrm{Y}$ \\
\hline Hospital Fixed Effects & Y & Y & $\mathrm{Y}$ & $\mathrm{Y}$ \\
\hline Surgeon Characteristics & Y & $\mathrm{N}$ & $\mathrm{Y}$ & $\mathrm{N}$ \\
\hline Surgeon Fixed Effects & $\mathrm{N}$ & $Y$ & $\mathrm{~N}$ & $\mathrm{Y}$ \\
\hline Number of Observations & 189444 & 189466 & 189444 & 189466 \\
\hline \multicolumn{5}{|c|}{$* * *$ signifies $\mathrm{p}<.001, * *$ signifies $\mathrm{p}<.01, *$ signifies $\mathrm{p}<.05$} \\
\hline \multicolumn{5}{|c|}{$\begin{array}{l}\text { Note: Columns } 1 \text { and } 2 \text { present estimates for specifications with the instrument calculated } \\
\text { under the equal allocation rule. Columns } 3 \text { and } 4 \text { present similar estimates for the Zip-code based rule. } \\
\text { Columns } 1 \text { and } 3 \text { exclude surgeon fixed effects but include surgeon characteristics instead. Standard } \\
\text { errors are robust and clustered by surgeon. }\end{array}$} \\
\hline
\end{tabular}


Table 5: Testing the Identification Assumption: Is Exit Volume Related to Surgeon Quality? Dependent Variable: Exit Volume faced by Surgeon

\begin{tabular}{|c|c|c|}
\hline & Equal Allocation & $\begin{array}{c}\text { Zip-code based } \\
\text { Allocation }\end{array}$ \\
\hline \multirow[t]{2}{*}{ Lagged Surgeon Quality } & 0.335 & 0.014 \\
\hline & 0.256 & 0.019 \\
\hline \multirow[t]{2}{*}{ Surgeon Age } & 0.004 & 0.002 \\
\hline & 0.038 & 0.007 \\
\hline \multirow[t]{2}{*}{ Female Surgeon } & 0.167 & 0.067 \\
\hline & 0.798 & 0.130 \\
\hline \multirow[t]{2}{*}{ Foreign Medical School } & -2.310 & 0.381 \\
\hline & 1.725 & 0.494 \\
\hline Year Fixed Effects & Y & Y \\
\hline Hospital Fixed Effects & Y & $\mathrm{Y}$ \\
\hline Number of Observations & 2708 & 2708 \\
\hline \multicolumn{3}{|c|}{$* * *$ signifies $\mathrm{p}<.001, * *$ signifies $\mathrm{p}<.01, *$ signifies $\mathrm{p}<.05$} \\
\hline \multicolumn{3}{|c|}{$\begin{array}{l}\text { Note: Unit of Observation is a surgeon at a hospital in a particular year. In Column 1, } \\
\text { the dependent variable (exit volume) is calculated using equal allocation, while Column } 2 \\
\text { uses the Zip-code based allocation method. Surgeon quality is measured using risk-adjusted } \\
\text { mortality rate. Standard errors in italics. }\end{array}$} \\
\hline
\end{tabular}


Table 6: Does Experience Affect All Surgeons Equally? (IV Estimates)

Dependent Variable: Did the patient die?

\begin{tabular}{|c|c|c|c|c|}
\hline \multirow[b]{2}{*}{ Surgeon CABG Volume, Prior Year } & \multicolumn{2}{|c|}{ Equal Allocation } & \multicolumn{2}{|c|}{ Zip-code based Allocation } \\
\hline & $-5.61 \mathrm{E}-05^{* *}$ & $-5.84 \mathrm{E}-05^{* *}$ & $-6.62 \mathrm{E}-05^{* * *}$ & $-7.03 \mathrm{E}-05^{* *}$ \\
\hline & 1.92E-05 & $1.88 E-05$ & $1.74 E-05$ & 2.16E-05 \\
\hline Surgeon Vol (Prior Year) * & $2.7 \mathrm{E}-05^{* *}$ & & $2.66 \mathrm{E}-05^{* *}$ & \\
\hline High Volume Surgeon & $1.01 E-05$ & & 8.90E-04 & \\
\hline Surgeon Vol (prior year) * & & $2.11 \mathrm{E}-06$ & & $2.45 \mathrm{E}-06^{*}$ \\
\hline Years since Graduation & & $1.31 E-06$ & & $1.14 E-06$ \\
\hline \multirow[t]{2}{*}{ Charlson Index } & $0.0023 * * *$ & $0.0020 * * *$ & $0.0024 * * *$ & $0.0027^{*}$ \\
\hline & 0.0004 & 0.0005 & 0.0004 & 0.0011 \\
\hline \multirow[t]{2}{*}{ Cardiogenic Shock } & $0.3175 * * *$ & $0.3166 * * *$ & $0.3183 * * *$ & $0.3090 * * *$ \\
\hline & 0.0029 & 0.0031 & 0.0029 & 0.0174 \\
\hline \multirow[t]{2}{*}{ Concurrent PTCA } & $0.0107 * * *$ & $0.0109 * * *$ & $0.0109 * * *$ & 0.015 \\
\hline & 0.0027 & 0.0028 & 0.0028 & 0.0102 \\
\hline \multirow[t]{2}{*}{ Hypertension } & $0.0213^{* * *}$ & $0.0222 * * *$ & $0.0215^{* * *}$ & 0.0109 \\
\hline & 0.004 & 0.0043 & 0.0041 & 0.0207 \\
\hline \multirow[t]{2}{*}{ Heart Failure } & $0.0270 * * *$ & $0.0270 * * *$ & $0.0271 * * *$ & $0.0267 * * *$ \\
\hline & 0.001 & 0.0011 & 0.001 & 0.0025 \\
\hline \multirow[t]{2}{*}{ Prior CABG } & $0.0255^{* * *}$ & $0.0241 * * *$ & $0.0253 * * *$ & $0.0341^{*}$ \\
\hline & 0.0019 & 0.0024 & 0.0019 & 0.0154 \\
\hline \multirow[t]{2}{*}{ Female } & $0.0129 * * *$ & $0.0130 * * *$ & $0.0129 * * *$ & $0.0131 * * *$ \\
\hline & 0.0009 & 0.001 & 0.0009 & 0.0022 \\
\hline \multirow[t]{2}{*}{ Heart Attack } & $0.0054 * * *$ & $0.0048 * * *$ & $0.0056 * * *$ & 0.0078 \\
\hline & 0.0011 & 0.0013 & 0.0011 & 0.0047 \\
\hline \multirow[t]{2}{*}{ Emergency Admission } & $0.0033 * *$ & $0.0036 * *$ & $0.0031 * *$ & 0.0088 \\
\hline & 0.0011 & 0.0011 & 0.0011 & 0.0103 \\
\hline Patient Age Categories & $\mathrm{Y}$ & $\mathrm{Y}$ & $\mathrm{Y}$ & $\mathrm{Y}$ \\
\hline Year Fixed Effects & $\mathrm{Y}$ & Y & $\mathrm{Y}$ & $\mathrm{Y}$ \\
\hline Hospital Fixed Effects & $Y$ & $Y$ & $Y$ & $Y$ \\
\hline Surgeon Fixed Effects & $\mathrm{Y}$ & $\mathrm{Y}$ & $\mathrm{Y}$ & $\mathrm{Y}$ \\
\hline Number of Observations & 189466 & 189444 & 189466 & 189444 \\
\hline
\end{tabular}

$* * *$ signifies $\mathrm{p}<.001, * *$ signifies $\mathrm{p}<.01, *$ signifies $\mathrm{p}<.05$

Note: Columns 1 and 2 present estimates for specifications with the instrument calculated under the equal allocation rule. Columns 3 and 4 present similar estimates for the Zip-code based rule. Standard errors are robust and clustered by surgeon. 
Table 7: Testing Specificity of Experience (IV Estimates)

Dependent Variable: Did the patient die?

\begin{tabular}{|c|c|c|c|c|}
\hline & \multicolumn{2}{|c|}{ Equal Allocation } & \multicolumn{2}{|c|}{ Zip-code based Allocation } \\
\hline \multicolumn{5}{|l|}{ Surgeon CABG Volume, Prior Year, Own } \\
\hline \multirow[t]{2}{*}{ Hospital } & $-6.23 \mathrm{E}-05^{*}$ & & $-6.18 \mathrm{E}-05^{* *}$ & \\
\hline & $2.97 E-05$ & & $2.34 E-05$ & \\
\hline \multicolumn{5}{|l|}{ Surgeon CABG Volume, Prior Year, Other } \\
\hline \multirow[t]{2}{*}{ Hospitals } & $-8.81 E-06$ & & $-7.42 \mathrm{E}-06 * *$ & \\
\hline & $5.10 E-06$ & & 2.77E-06 & \\
\hline \multirow[t]{2}{*}{ Surgeon CABG Volume, Prior Year } & & $-5.91 \mathrm{E}-05^{* *}$ & & $-5.29 \mathrm{E}-05 * * *$ \\
\hline & & $2.11 E-05$ & & $1.44 E-05$ \\
\hline \multirow[t]{2}{*}{ Surgeon non-CABG Volume, Prior Year } & & $-4.03 E-06 *$ & & $-3.14 \mathrm{E}-06 * *$ \\
\hline & & $1.64 E-06$ & & $1.04 E-06$ \\
\hline Patient Characteristics & Y & $\mathrm{Y}$ & $\mathrm{Y}$ & Y \\
\hline Year Fixed Effects & $\mathrm{Y}$ & Y & $\mathrm{Y}$ & Y \\
\hline Hospital Fixed Effects & $\mathrm{Y}$ & Y & Y & $\mathrm{Y}$ \\
\hline Surgeon Fixed Effects & Y & Y & $\mathrm{Y}$ & $\mathrm{Y}$ \\
\hline Number of Observations & 184960 & 187618 & 184960 & 187618 \\
\hline
\end{tabular}

$* * *$ signifies $\mathrm{p}<.001, * *$ signifies $\mathrm{p}<.01, *$ signifies $\mathrm{p}<.05$

Note: Columns 1 and 3 present tests for firm specificity of experience, under the equal and zip-code based allocation rules, respectively. Columns 2 and 4 present tests for task-specificity. The difference in number of observations across columns is due to surgeons performing only non-CABG procedures in some years. Standard errors and robust and clustered by surgeon. 
Table 8: Some Robustness Checks

Dependent Variable: Did the Patient die?

\begin{tabular}{|c|c|c|c|c|c|}
\hline & $\begin{array}{c}\text { (1) } \\
\text { Alt. Def. }\end{array}$ & $\begin{array}{c}(2) \\
2 \text { Year }\end{array}$ & $\begin{array}{c}\text { (3) } \\
\text { Cumulative }\end{array}$ & $\begin{array}{c}\text { (4) } \\
\text { No Control }\end{array}$ & $\begin{array}{c}\text { (5) } \\
\text { Surg-Hosp }\end{array}$ \\
\hline \multirow[t]{2}{*}{ Total Surgeon Volume, prior year } & $-4.58 \mathrm{E}-05^{* *}$ & $-5.48 \mathrm{E}-05^{*}$ & $-2.87 \mathrm{E}-05$ & $-6.24 \mathrm{E}-05^{*}$ & $-5.15 \mathrm{E}-05^{* *}$ \\
\hline & $1.68 E-05$ & $2.66 E-05$ & $3.55 E-05$ & $2.77 E-05$ & $1.77 E-05$ \\
\hline Patient Characteristics & Y & Y & Y & $\mathrm{N}$ & Y \\
\hline Surgeon Characteristics & $\mathrm{N}$ & $\mathrm{N}$ & $\mathrm{N}$ & $\mathrm{N}$ & $\mathrm{N}$ \\
\hline Hospital Fixed Effects & $\mathrm{Y}$ & Y & Y & Y & $\mathrm{N}$ \\
\hline Surgeon Fixed Effects & Y & Y & Y & $\mathrm{Y}$ & $\mathrm{N}$ \\
\hline Surgeon $\mathrm{x}$ Hospital dummies & $\mathrm{N}$ & $\mathrm{N}$ & $\mathrm{N}$ & $\mathrm{N}$ & Y \\
\hline Number of Observations & 189466 & 160441 & 18663 & 189466 & 189466 \\
\hline
\end{tabular}

$* * *$ signifies $\mathrm{p}<.001, * *$ signifies $\mathrm{p}<.01, *$ signifies $\mathrm{p}<.05$

Note: All columns present results of IV regressions of patient mortality on surgeon's CABG procedure volume. Column 1 relaxes the age restriction in the exit definition. Columns 2 and 3 use procedure volume from the last 2 years and cumulative volume respectively instead of prior year volume as the measure of surgeon experience. Column 4 estimates the model with only fixed effects and no control variables. Column 5 estimates the model with surgeon-hospital fixed effects. All columns use the instrument constructed using the zip-code based allocation rule. 